\title{
Experimental Investigation on Mechanical Joint of Lontar (Borassus Flabellifer) Fiber Reinforced Polyester Composites under Static Flexural Test
}

\author{
Jefri S. Bale ${ }^{1 凶}$, Yeremias M. Pell ${ }^{1}$, Muhamad Jafri ${ }^{1}$, Rima Selan $^{1}$ \\ ${ }^{1}$ Mechanical Engineering Department, Faculty of Mechanical Engineering, Universitas Nusa Cendana, 85001 \\ Kupang, Nusa Tenggara Timur, Indonesia \\ ${ }^{凶}$ Correspondence: E-mail: jefri_bale@staf.undana.ac.id
}

\section{A B S TRACT}

This study has been conducted to investigate the flexural strength of Borassus Flabellifer Fiber (BFF) reinforced polyester composite joint under static condition. Tests were carried out to study the flexural strength of double strap butt joint and single lap joint of BFF polyester composite. In addition, post observation of macroscope was used to map failure behavior. The results showed that the flexural strength of single lap joint is higher than that of material with double strap butt joint of BFF polyester composite. The larger cross-sectional area and the existence of gap area could be the main reason for lower flexural strength generated by double strap butt joint of BFF polyester composite. The failure of BFF polyester composite joints under flexural test indicated the brittle failure behaviour. Fiber breakage was found to be the final failure mechanism, starting with matrix crack and fiber-matrix debonding failure mechanisms.

(c) 2019 Tim Pengembang Jurnal UPI
\end{abstract}

\begin{tabular}{l}
\hline A R T I C L E I N F O \\
\hline Article History: \\
Submitted/Received 23 Aug 2018 \\
First Revised 11 Des 2018 \\
Accepted 02 Feb 2019 \\
First available online 09 Feb 2019 \\
Publication date 01 Apr 2019 \\
\hline Keywords: \\
Borassus flabellifer, \\
Mechanical joint, \\
Flexural strength, \\
Fiber Composite.
\end{tabular}

\section{INTRODUCTION}

Nowadays, composite materials have been attracted attentions for more finding and more applications in automotive, aerospace, construction, sport, and packaging industries (Mohan et al., 2012). In practical use of composite materials as a joint component of construction, mechanical joints are the discontinuity geometry to facilitate the assembly of the bolt or rivet holder. From a mechanical point of view, the joint structure is a critical area causing the stress concentration, the initial occurrence of damage propagation and the final failure of the composite component (Bale et al., 2018; 
Chang et al., 2006; Senguttuvan and Lillymercy, 2015). Therefore, the stress concentration impacts on various types of mechanical joint is an important issue, especially in evaluating the damage and failure of composite materials, which may later affect the mechanical strength and the lifetime of the composite materials component.

Composite materials based on renewable and natural resources are potential due to their ecofriendly nature and sustainability (Mohammed et al., 2015). Natural fiber is a type of renewable sources and a new generation of reinforcements for composite materials, and the development of natural fiber composite materials has been a hot topic recently due to the increasing environmental awareness (Sanjay et al., 2016). The advantages of natural fibers include low price, low density, unlimited, sustainable availability, and low abrasive wear of processing machinery (Malkapuram et al., 2008). Further, natural fibers are recyclable, free of carbon dioxide and environmentally friendly (Biswas et al., 2012; Ahmad et al., 2013).

Recently, lontar or Borassus flabellifer fiber (BFF) is used as the reinforcement material due to their availability, low cost, and environmentally friendly nature. Therefore,, BFF is increasingly in demand by many researchers for being used and applied as composite materials. The mechanical properties of BFF could be enhanced by alkali treatment and could be used as reinforcement in the composites to fabricate light weight parts for structural applications like automobile door panels, window frames, etc (Boopathi et al., 2012; Srinivasababu et al., 2014; Sudhakara et al., 2013; Obi Reddy et al., 2013). In orthotics, BFF had good potential to be applied as the orthotic devices due to its properties (Shanmugam and Thiruchitrambalam, 2013). Based on the fabrication process of Borassus fruit fiber/pp composites, it was found that the 5 wt\% compatibilizer by injection molding and 15 wt\% of BFF are the optimum concentration for composites fabrication (Sarasini et al., 2017). The effect of the hole on tensile strength of lontar fiber reinforced composite indicated that the local area from the existence of hole dictates the tensile strength and the presence of the hole initiates the damage propagation of matrix cracking which fairly straight and transverse to the loading axis (Bale et al., 2017).

The use of BFF in composite materials as the reinforcement has presented the need to understand its material properties by conducting mechanical tests. The results obtained can be the basic references to apply the BFF reinforced polymer composite material in joint structure application for automotive or marine industry. However, the study of BFF reinforced polymer composite is a challenging task since very limited work has been done on its application on mechanical joint design. The present work thus focuses on the investigation of mechanical joint by using polymer matrix composites and BFF as the reinforcement under flexural load in static condition.

\section{MATERIALS AND METHODS}

\subsection{Fiber preparation.}

BFF were first chopped to length of $5 \mathrm{~cm}$ and washed with distilled water until the removal of attached physical impurities are on BFF surface. Then, the BFF were dried for 24 hours at ambient temperature. Further, BFF preparation was alkali treatment using $5 \%$ of $\mathrm{NaOH}$ for 1 hour at room temperature. Alkali treatment removed fibre constituents and increased surface roughness for improving the bonding between fiber and a matrix (Pickering et al. 2015). The BFF later were washed with distilled water to remove any $\mathrm{NaOH}$ sticking on its surface, and then the BFF were room dried again for 24 hours. 
Detailed information for BFF is shown in Figure 1.

\subsection{Specimen Preparation.}

The fabrication of the joints were carried out through the hand lay-up technique. The random fiber orientation of BFF was applied as the reinforcement and polyester was used as the matrix. They are mixed with $30 \%$ of BFF volume fraction and $70 \%$ of polyester volume fraction. The mixture of the polyester and the catalyst were poured into the mold together with the BFF in accordance with the ratio of the volume fraction to obtain the desired composite plates $\left(300 \times 300 \mathrm{~mm}^{2}\right)$ with the thickness of $4 \mathrm{~mm}$. Each composite plate was cured at room temperature under a load of about $50 \mathrm{~kg}$ for 24 hours before it is removed from the mould. The composite plates were then cut out in accordance with the ASTM D5961 where each specimen should have centerline holes so it can be connected using a nut and bolt. In order to investigate the bending properties of mechanical joint, two types of joint were studied, i.e. double strap butt joint and single lap joint, shown in Figure 2. Ten specimens of each type of joint were tested and the results were presented as an average value of tested specimens.

\subsection{Flexural test.}

The specimens were subjected to fourpoint bending test using the Torse Universal Testing Machine Type AMU-5-DE. The two loading pins are placed at an equal distance around the center of span length of $170 \mathrm{~mm}$ and the cross head speed of $2 \mathrm{~mm} / \mathrm{min}$ were maintained. Based on the data obtained from the tests, the analysis will be performed to determine the BFF polyestercomposite joints. Figure $\mathbf{3}$ shows the flexural test configuration.

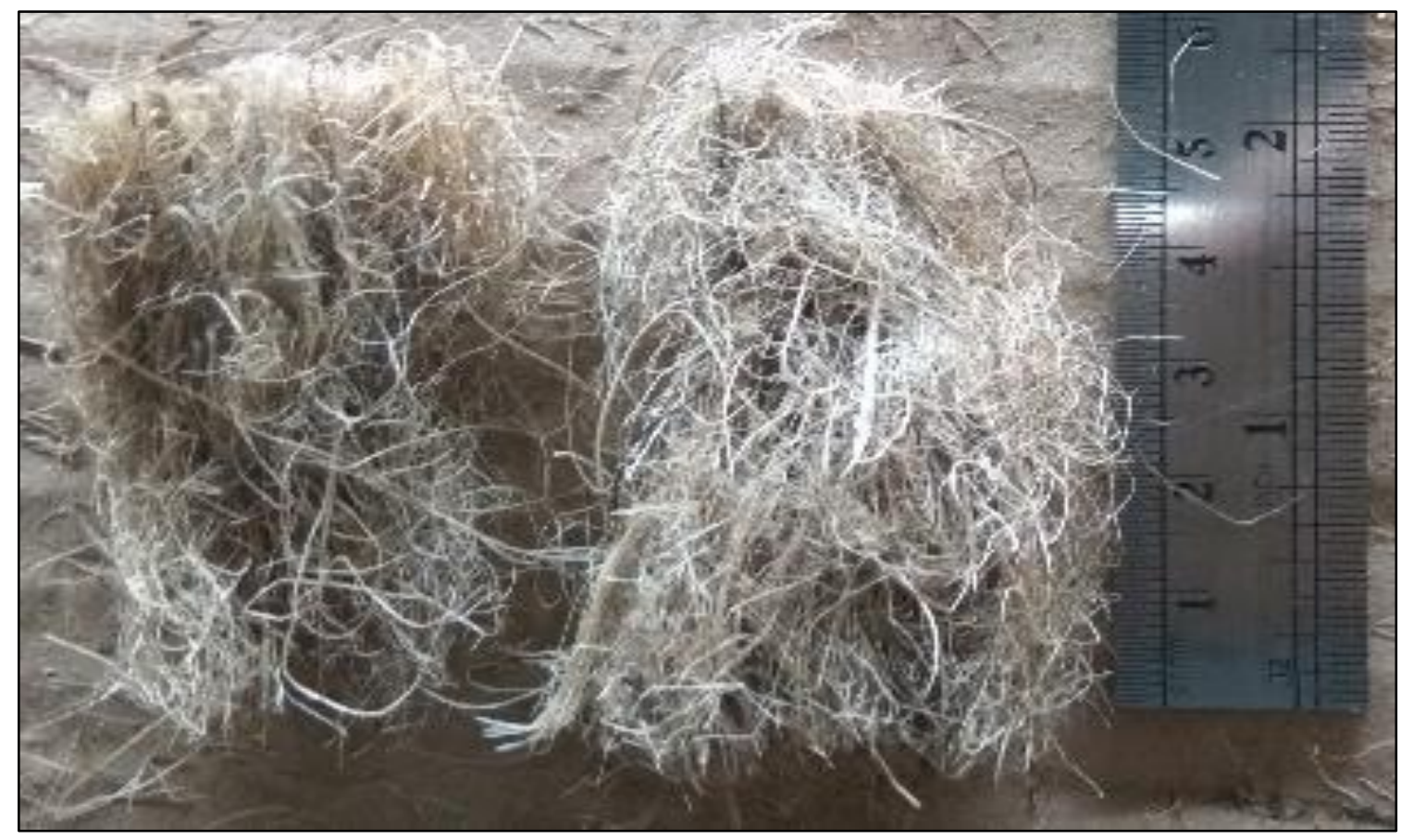

Figure 1. Borassus Flabelliferfiber 


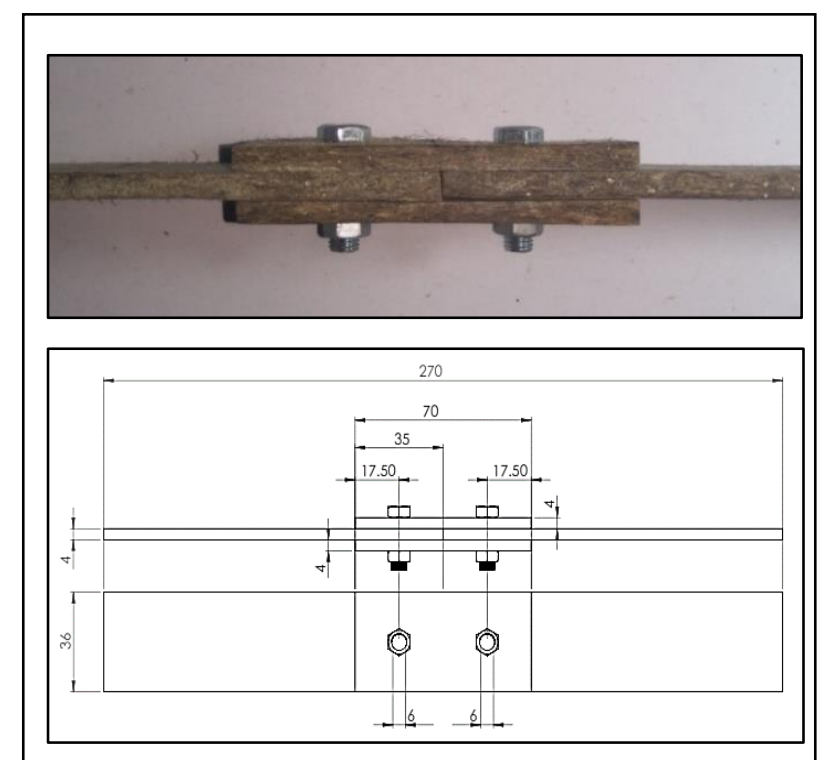

a. Double strap butt joint of BFF polyester composite
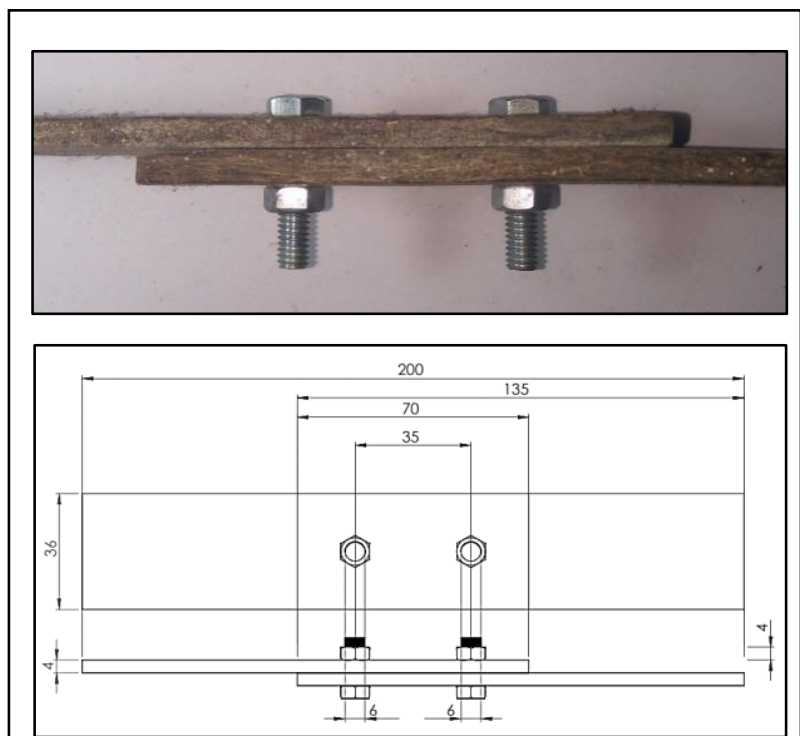

b. Single lap joint of BFF polyester composite

Figure 2. BFF polyester composite joint (in mm)

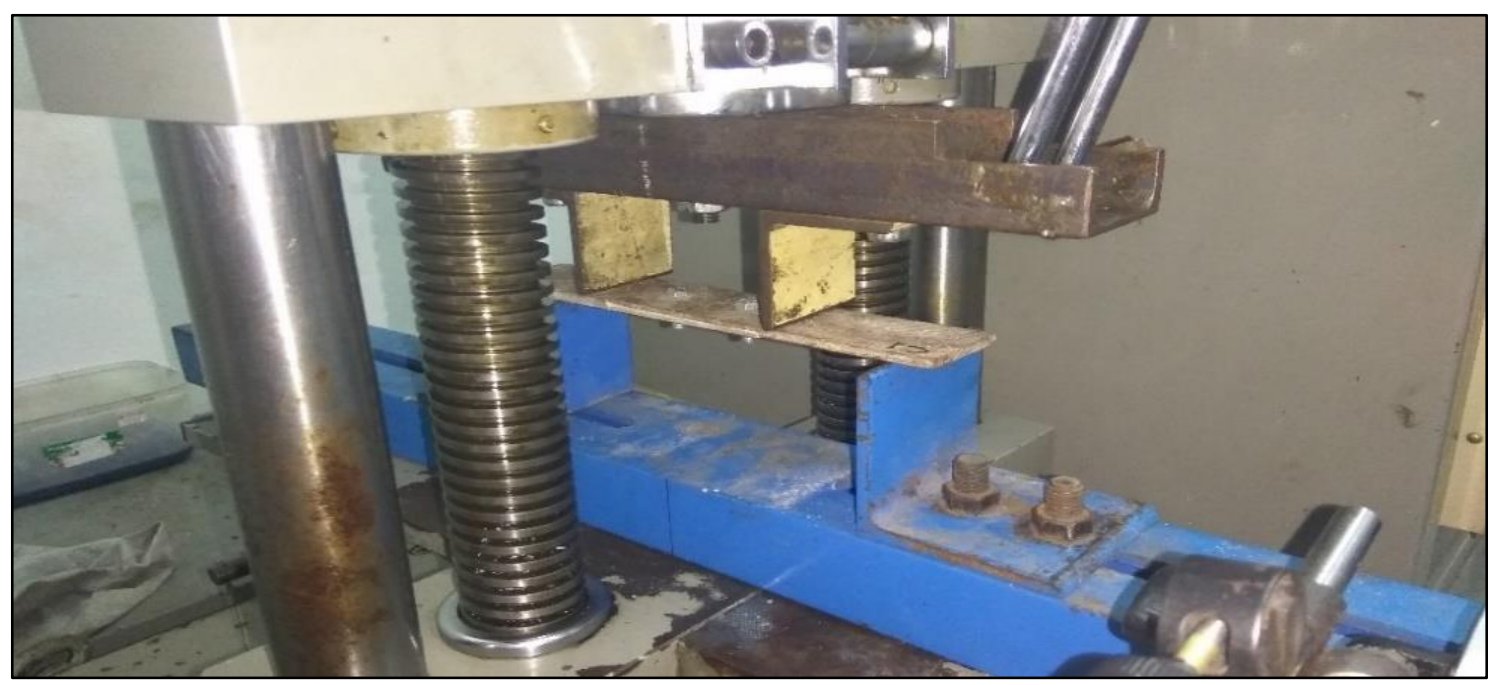

Figure 3. Flexural test configuration

\section{RESULTS AND DISCUSSION}

\subsection{Flexural strength}

The flexural tests were performed on test specimen of mechanical joint of BFF polyester composite i.e. double strap butt joint and single lap joint. From the tests results, obtained the average data of the maximum load $(\mathrm{N})$ and deflection $(\mathrm{mm})$ of each BFF polyester composite joint, shown in Figure 4.

DOI:http://dx.doi.org/10.17509/ijost.v4i1.15239| p- ISSN 2528-1410 e- ISSN 2527-8045 | 
From the tests results, the higher average static flexural maximum load of BFF polyester composite joint is $490 \mathrm{~N}$ which resulting by single lap joint. The lower static flexural maximum load of $340 \mathrm{~N}$ is recorded for double strap butt joint. The maximum deflection of $18 \mathrm{~mm}$ also produced by single lap joint and double strap butt joint resulting minimum deflection of $15 \mathrm{~mm}$.

Figure 5 shows the typical loaddeflection curve for each mechanical joint of BFF polyester composite. Basically, two different stages can be observed from the load-deflection curve: first stage represents the likely linear increment period.

This load-deflection behaviour occurs due to the negligible stiffness change until the maximum load; second stage illustrates the decrease capability period of loadcarrying that describe the evolution of flexural damage.

The linear fitting (red and yellow line) was plotted on the curve for each stage to describe the stiffness reduction due to the damage appearance at the lines intersection. This behaviour also explained in Arnautov et al. (2015), in which they found in loaddisplacement curve of double-lap shear (DLS) tests for welding and fastening composite joint. The flexural strength of BFF polyester composite joint is presented in Figure 6 . It shows that the flexural strength of the single lap joint of BFF polyester composite is approximately $50 \%$ higher than double strap butt joint of BFF polyester composite.

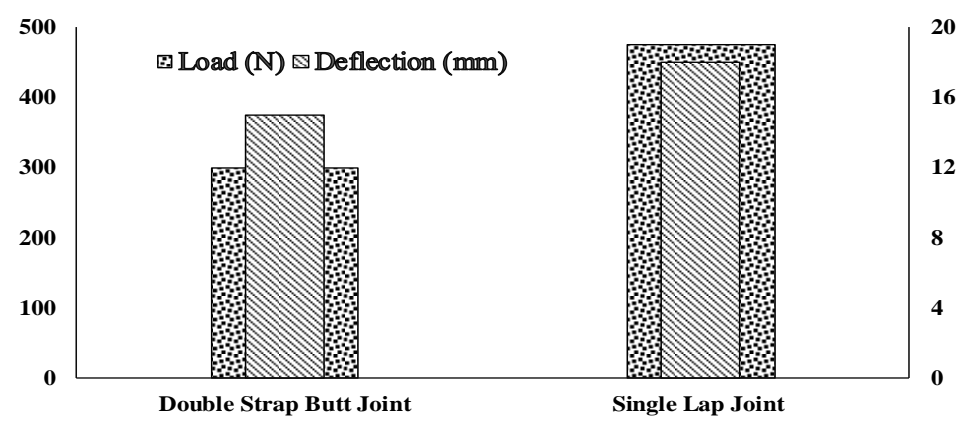

Figure 4. Load and deflection of BFF polyester composite joint

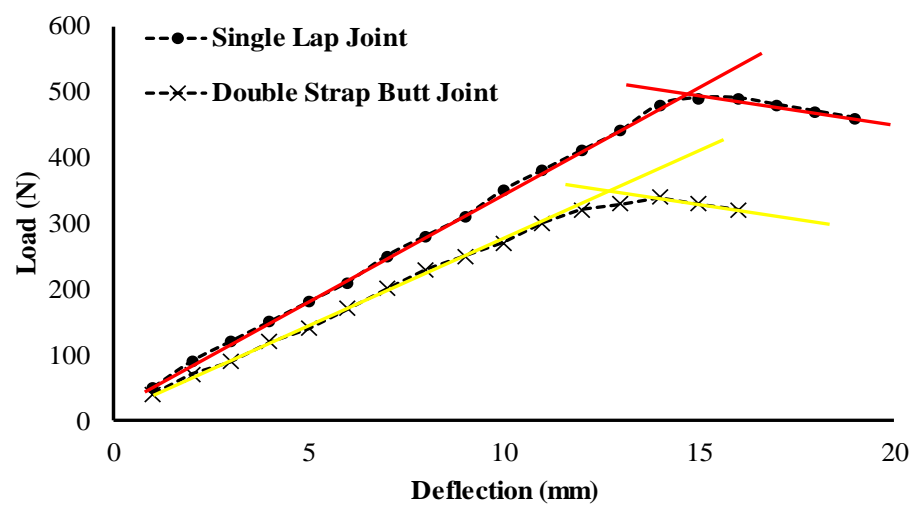

Figure 5. Load-deflection curve of mechanical joint of BFF polyester composite 


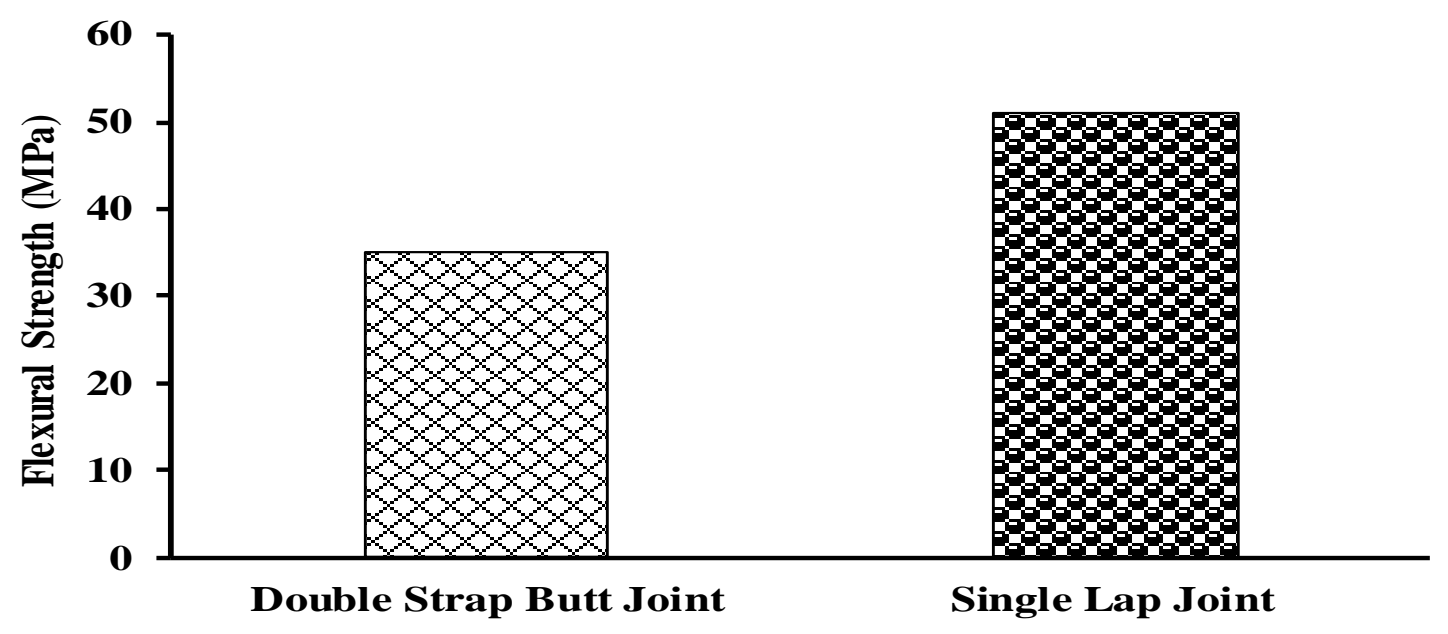

Figure 6. Flexural strength of BFF polyester composite joint

The double strap butt joint of BFF composite specimens have larger crosssectional area due to the existence of strap plates compared to the single lap joint specimens. Theoritically, the difference of cross-sectional area affects the bending stress calculation where it is inversely proportional to the stress calculation. This phenomenon was also confirmed by previous study (Bale et al., 2017), where the smaller area of joint configuration due to the presence of the hole produces larger tensile stress compared to the joint configurations with larger area. Furthermore, the stress behaviour shows that the single lap joint of BFF polyester composite possessed better strength to withstand the absorbed energy generated from the load to deform than the the double strap butt joint. The composite strength detected by the absorbed energy has been investigated using infra-red (IR) camera during the testing where the results shown that the more energy absorbed indicates that the fiber composite has a better strength and ability to transfer the load before damage that is signed by slowly released of the absorbed energy (Montesano et al., 2013; Bale et al., 2017). From the geometry point of view, double strap butt joint produces the lower flexural strength possibly due to the presence of higher stress concentration at the gap area of adherend part in black circle, as shown in Figure 7. Around the gap area, there is no adhesive used. This causes the concentration and distribution of the stress at the end of adherent part/discontinuity part can not be distributed so that the flexural load can only be transferred by the strap plates. In addition, the presence of adhesive in the gap area has an influence on the strength of the joints as explained by previous studies (Karachaliosa et al., 2013; Temiz and Adin, 2015; Patil and Choudhari, 2016), where the joint strength increases as the adhesive thickness increases. The flexural modulus of BFF polyester composite joints indicates the stiffness and the deflection behaviour, as shown in Figure 8. The higher deflection is also followed by an increase of the flexural modulus, where the average flexural modulus of the single lap joint was generated to be around $20 \%$ higher compared to the the double strap butt joint. This indicates that the load of single lap joint was distributed more uniformly in the sufficient area before damage compared to the double strap butt joint. 


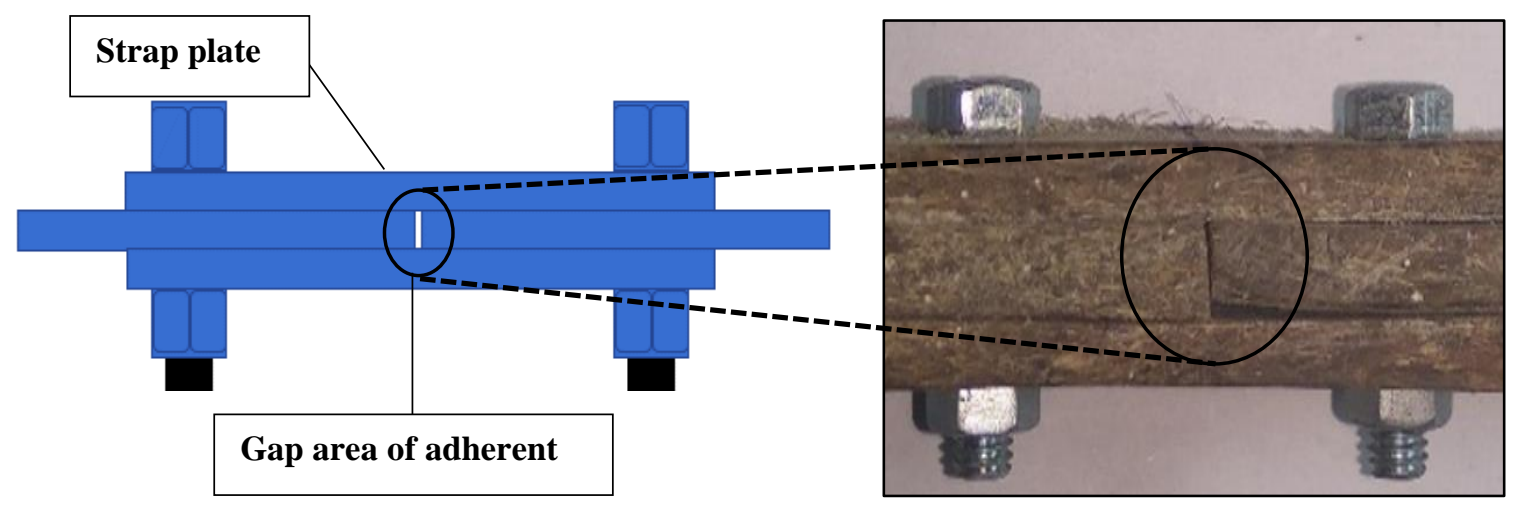

Figure 7.Geometry ilustration of double strap butt joint of BFF polyester composite

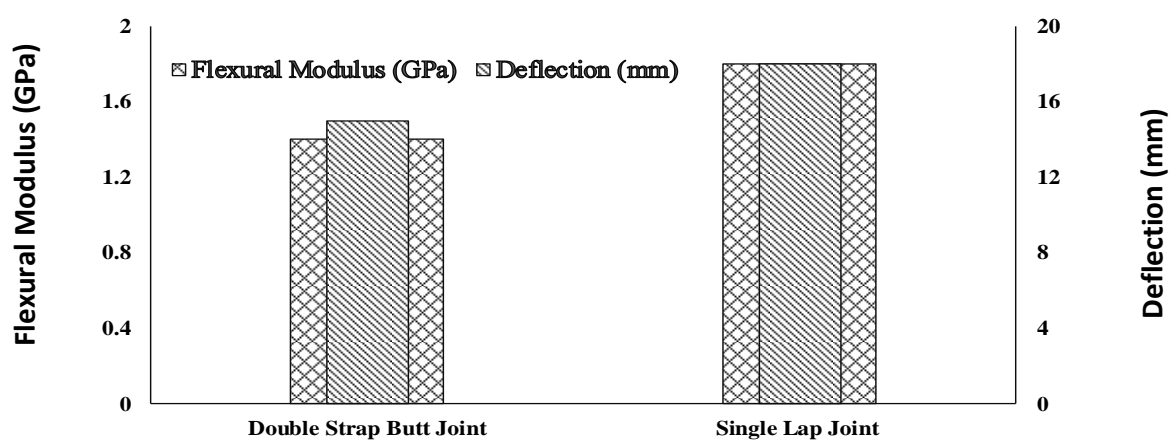

Figure 8.Fexural modulus of BFF polyester composite joints

Consequently, single lap joint generates higher deflection rather than double strap butt joint. On the other hand, the existance of gap area of double strap butt joint also possibly is the main cause for lower deflection and flexural modulus, as reported in the literature (Bale et al., 2018). Eliminating the existence of gap area of strap butt joint improves the joint strength by filling the gap area with adhesive and creating intact area to carry out the applied load (Sandu et al. 2010; Temiz et al., 2015). This is reasonable since the single lap joint acts entirely rely on the intact area due to the absence of gap area and contributes to higher toughness, as opposed to the double strap butt joint.

\subsection{Damage behaviour}

Under flexural loading, the failure stage of BFF polyester composite joints is illustrated in Figure 9(a). From the damage observation of both types of BFF polyester composite joints, it can be seen that the failure propagates perpendicular to the specimen length and no change of shape or geometry (pure elastic deformation), which is the characteristic of brittle fracture. The failure location for both joints were found to occur at critical regions, i.e. the end of strap plate of double strap butt joint and the end of overlap adherend part of single lap joint, as also reported in previous studies (Calik 2016; Temiz 2006). The fiber breakage and matrix rupture found to be the final failure mechanism for both types of BFF polyester composite joints, in which this normally started with matrix cracking in micro scale at the tensile side of the specimen. Along with the increase of flexural load during the test, it propagates and then leads to initiate the presence of fiber-matrix debonding damage mechanism that can result in final failure of its structure, as presented in Figures $\mathbf{9 ( b )}$ and (c). This damage behaviour also explained by others literatures (Leão et.al., 2011; Meihong et.al., 2016), which is a typical brittle damage of fiber composite. 


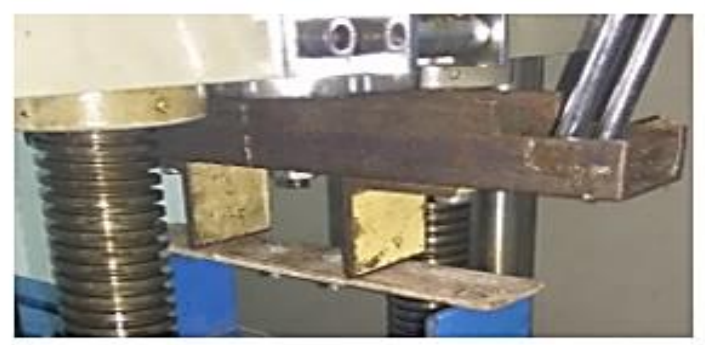

Stage 1 : Initial condition

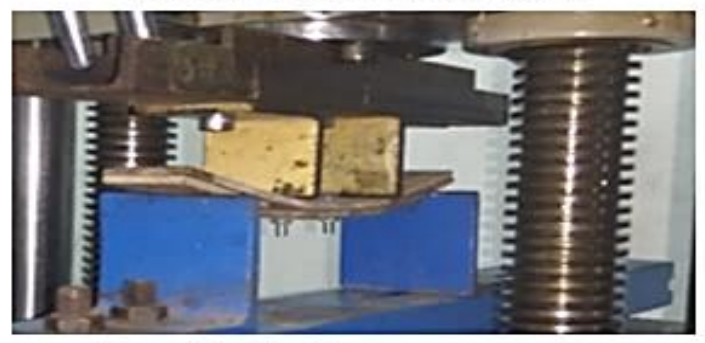

Stage 3 : Failure propagation

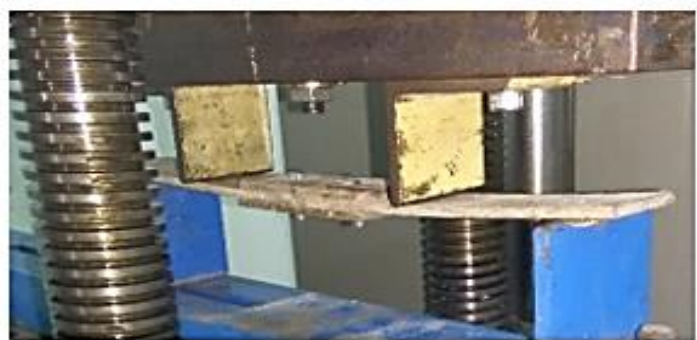

Stage 2 : Initial failure of matrix cracking

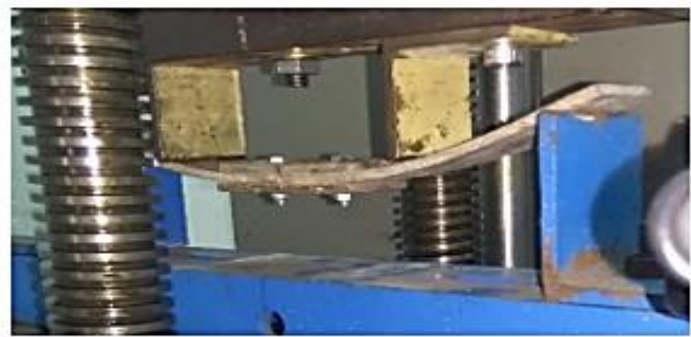

Stage 4 : Final failure condition

a. Failure stage

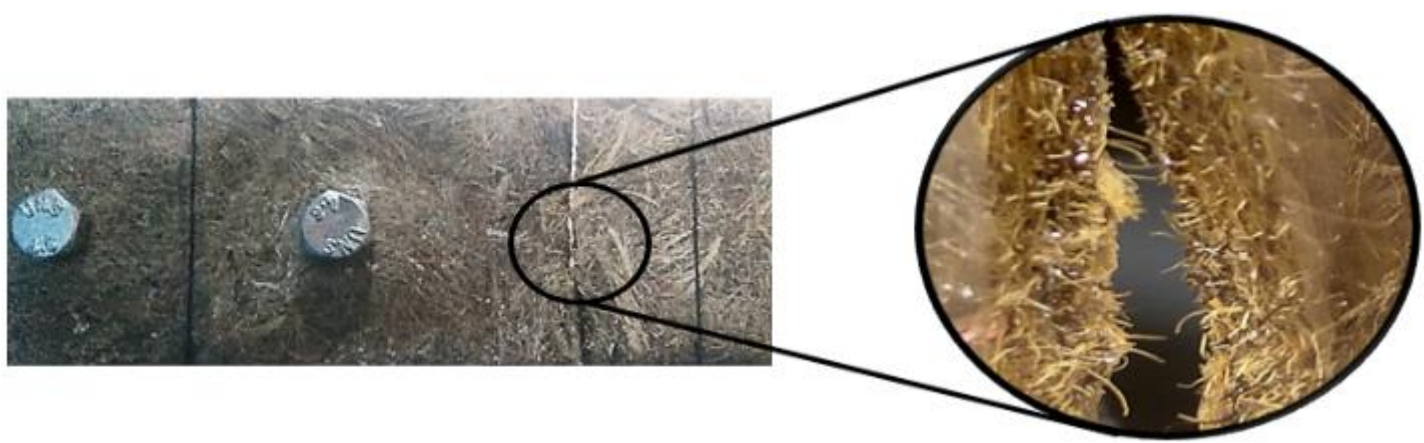

b. Failure of single lap joint

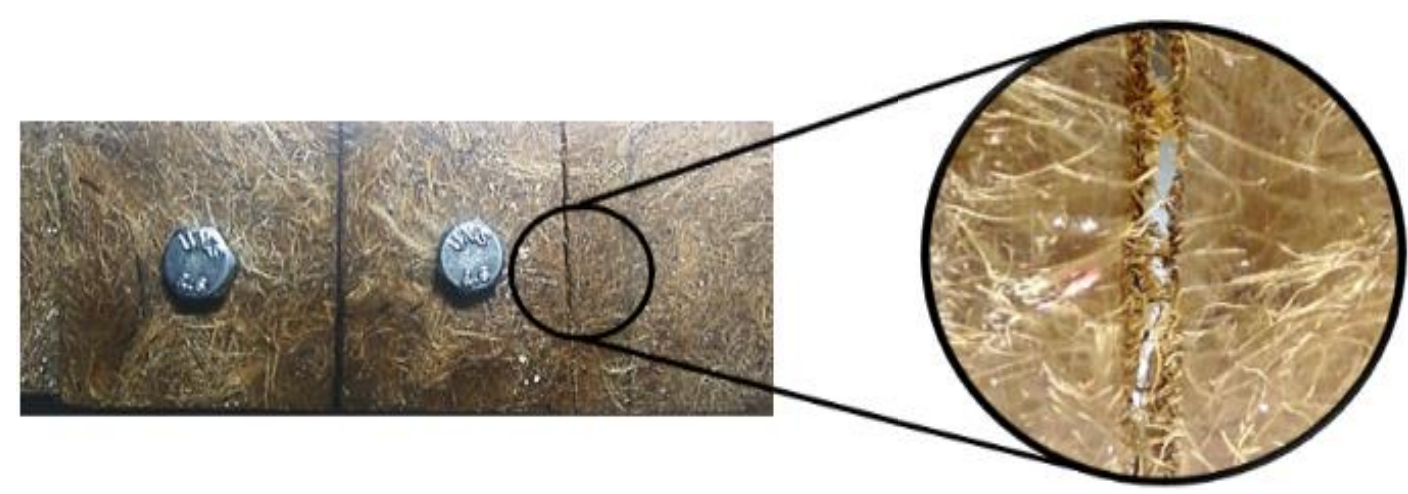

c. Failure of strap butt joint

Figure 9. Failure of BFF polyester composite joints 


\section{CONCLUSION}

The flexural behaviour of BFF polyester composite of single lap joint was found higher compared to the double strap butt due to the presence of the stress concentration and uneven stress distribution at sufficient area. Fiber breakage and matrix rupture found to be the final failure for both joints where initiated by matrix cracking and fiber-matrix debonding.

\section{ACKNOWLEDGEMENTS}

The authors would like to express their thanks to the Indonesian ministry of research, technology and higher education (Kemenristekdikti Indonesia) for funding this research under the program of fundamental research 2018 (No. 78/UN15.19/LT/2018).

\section{AUTHORS' NOTE}

The authors declare that there is no conflict of interest regarding the publication of this article. Authors confirmed that the data and the paper are free of plagiarism.

\section{REFERENCES}

Ahmad Thirmizir, M.Z., Mohdlshak, Z.A., Mat Taib, R., and Rahim, S. (2013). Effect of maleatedcompatibiliser (PBS-g-MA) addition on the flexural properties and water absorption of poly(butylene succinate)/kenafbast fibre composites. Sains Malaysiana, 42(4), 435-441.

Arnautov, A., Nasibullins, A., Gribniak, V., Blumbergs, I., and Hauka, M. (2015). Experimental characterization of the properties of double-lap needled and hybrid joints of carbon/epoxy composites. Materials, 8, 7578-7586.

Bale, J., Adoe, D.G.H., Boimau, K., and Sakera, T. 2018. The tensile strength of mechanical joint prototype of lontarfiber composite. IOP Conference Series: Materials Science and Engineering, 316, 1-10.

Bale, J., Boimau, K., and Nenobesi, M. 2017. Natural composite reinforced by bontar (borassusflabellifer) fiber: An experimental study on open-hole tensile strength. International Journal of Biomaterials, 2017, 1-8.

Bale, J., Valot, E., Polit, O., Bathias, C., Monin, M., and Soemardi, T. (2017). Thermal phenomenon of glass fibre composite under tensile static and fatigue loading. Journal of Mechanical Engineering and Sciences Volume 11 (2): 2755-2769.

Biswas, S., Kindo, S., and Patnaik, A. (2011). Effect of fiber length on mechanical behavior of coir fiber reinforced epoxy composites. Fibers and Polymers, 12(1), 73-78.

Boopathi, L., Sampath, P.S., and Mylsamy, K. (2012). Investigation of physical, chemical and mechanical properties of raw and alkali treated Borassus fruit fiber. Composites: Part $B$, 43, 3044-3052.

Calik, A. (2016). Effect of adherend shape on stress concentration reduction of adhesively bonded single lap joint. Engineering Review, 36 (1), 29-34.

Chauhan, A., Chauhan, P., and Kaith, B. (2012). Natural fiber reinforced composite: A concise 
review article. Journal of Chemical Engineering and Process Technology, 3(2), 10001323.

Chang, P., Mouritz, A.P., and Cox B.N. 2006. Properties and failure mechanisms of pinned composite lap joint in monotonic and cyclic tension. Composites Science and Technology, 66, 2163-2176.

Karachaliosa, E.F., Adams, R.D., and da Silva, L.F.M. 2013. The behaviour of single lap joints under bending loading. Journal of Adhesion Science and Technology, 27(16), 1811-1827.

Leão, M.A., Tinô, S.R.L., Fontes, R.S., and De Aquino, E.M.F. (2011). Bending in laminas of nfpr: Type of reiforcement, fracture and properties. Material Research 14(1), 67-72.

Malkapuram, R., Kumar, V., and Yuvraj, S.N. (2008). Recent development in natural fibre reinforced polypropylene composites. Journal of Reinforced Plastics and Composites, 28, 1169-1189.

Meihong, H., Yang, T., Niu, X., and Yu, D. (2016). Experimental Investigation of the Threepoint Bending Fatigue Properties of Carbon Fiber Composite Laminates. Advances in Material Science, 1, 1-10.

Mohammed, L., Ansari, M. N., Pua, G., Jawaid, M., and Islam, M. S. (2015). A review on natural fiber reinforced polymer composite and its applications. International Journal of Polymer Science, 2015, 1-10.

Mohan, T.P., and Kanny, K. (2011). Water barrier properties of nanoclay filled sisal fibre reinforced epoxy composites. Composites Part A, 42(4), 385-393.

Montesano, J., Fawaz, Z., and Bougherara, H. (2013). Use of infrared thermography to investigate the fatigue behavior of a carbon fiber reinforced polymer composite. Composite Structures, 97, 76-83.

Obi Reddy, K., Uma Maheswari, C., Shukla, M., Song, J.I., and VaradaRajulu, A. (2013). Tensile and structural characterization of alkali treated Borassus fruit fine fibers. Composites Part $B, 44,433-438$.

Patil, S.A., and Choudhari, C.S. (2016). A review of strength analysis of adhesively bonded single. International Research Journal of Engineering and Technology, 3(7), 10-15.

Pickering, K.L., Aruan Efendy, M.G., and Le, T.M. (2016). A review of recent developments in natural fibre composites and their mechanical performance. Composites Part $A, 83,98-$ 112.

Sandu, M., Sandu, A., and Constantinescu, D.M. (2010). Strength of adhesively bonded singlestrapped joints loaded in tension. Proceedings of the Romanian Academy Series A, 11 (4), 371-379.

Sanjay, M.R., Arpitha, G.R., Naik, L.L., Gopalakrishna, K., and Yogesha, B. (2016). Applications of natural fibers and its composites: An overview. Natural Resources, 7, 108-114.

Sarasini, F., Tirillò, J., Puglia, D., Dominici, F., Santulli, C., Boimau, K., and Valente, T. (2017) Biodegradable polycaprolactone-based composites reinforced with ramie and borassus fibres, Composite Structures, 167, 20-29. 
Senguttuvan, N., and Lillymercy, J. (2015). Joint strength analysis of single lap joint in glass fiber composite material. International Journal of Applied Engineering Research, 10(7), 16535-16545.

Shanmugam, D., and Thiruchitrambalam, M. (2013). Static and dynamic mechanical properties of alkali treated unidirectionalcontinuous palmyra palm leaf stalk fiber/jute fiber reinforced hybridpolyester composites. Materials and Design, 50, 533-542.

Srinivasababu, N., Kumar, J.S., and Reddy, K.V.K. (2014). Manufacturing and characterization of long palmyra palm/borassusflabellifer petiole fibre reinforced polyester composites. Procedia Technology, 14, 252-259.

Sudhakara, P., Jagadeesh, D., Wang, Y.Q., Prasad, C.V., Kamala Devi, A.P., Balakrishnan, G., Kim, B.S., and Song, J.I. (2013). Fabrication of borassus fruit lignocellulose fiber/pp composites and comparison with jute, sisal and coir fibers. Carbohydrate Polymers, 12, 1002-1010.

Temiz, S. (2006). Application of bi-adhesive in double-strap joints subjected to bending moment. Journal of Adhesion Science and Technology, 20(14), 1547-1560.

Temiz, S., Adin, H., and Sulu, I.Y. (2015). Behaviour of bi-adhesive in double-strap joint with embedded patch subjected to bending. Journal of Theoretical and Applied Mechanics, 45(3), 83-96. 